\title{
Headaches Induced by Pornography Use
}

\author{
Kuljeet Singh Anand • Vikas Dhikav
}

Published online: 14 June 2012

(c) Springer Science+Business Media, LLC 2012

\begin{abstract}
A 24-year-old unmarried male software professional, not a known case of diabetes orhypertension, presented with episodes of severe, exploding holocranial headache on watching pornographic videos for the last 2 years. The headache would develop gradually over $5 \mathrm{~min}$ of viewing videos and would peak within $8-10 \mathrm{~min}$. The intensity was so severe that he had to abort watching. There was no accompanying nausea, vomiting, or phonophobia. Progressively, he started to refrain from viewing videos as a means of avoiding headaches. There was nohistory of headache associated either with masturbation or with coitus. He had no history of head injury or meningoencephalitis in early childhood. There was no history suggestive of migraine in the family. He did not have a history suggestive of migraine, tension type or exertional headache. A physical and systemic examination was unremarkable. The neurological examination was normal. Magnetic Resonance (MR) Imaging, MR angiography of brain, and electroencephalogram were normal. He was advised non-steroidal anti-inflammatory agent combination (ibuprofen $400 \mathrm{mg}$ and paracetamol $500 \mathrm{mg}$ ) half an hour before watching, to which he reported significant pain relief.
\end{abstract}

Headaches associated with sexual activity are uncommon (Anand \& Dhikav, 2009). Pre-orgasmic headache may be related tospace-occupying lesions. Orgasmicheadacheis often severe and excruciating, whether due to aneurysm rupture or to the explosive component of benign coital headache. Post-orgasmic headache may occurasamanifestation of migraine(Banerjee, 1996). A study by Frese et al. (2003) stratified headaches associated with sexual activity and found that there was a male preponderance. It has two onset peaks (between 20-24 and 35-44 years). It can be dull type, increasing gradually with sexual excitement or explosive type. Pain can be bilateral and diffuse or occipital. Headache associated with sexual activity has not been shown to be dependent upon specific sexual habits and occurs often after having sexual activity with partner or during masturbation. There was a high co-morbidity with migraine and other types of headaches (e.g., benign exertional and tension-type). The mechanismof headacheinduced by sexual activity is mainly a trigeminal-vasculareffect, but there is a definite muscular component (Anand \& Dhikav, 2009). Muscularcontraction plays a major role, especially in milderheadaches that become more intense as the sexual excitement increases. The probable mechanisms behind occurrence of headache in the present case could be alteration of nocioceptive mechanisms in the trigemino-vascular system with increased pain sensitivity associated with a heightened emotional state associated with viewing pornorgraphy.

\section{References}

Anand, K. S., \& Dhikav, V. (2009). Primary headache associated with sexual activity. Singapore Medical Journal, 50(5), e176-e177.

Banerjee, A. (1996). Coital emergencies. Postgraduate Medical Journal, 72, 653-656.

Frese, A., Eikermann, A., Frese, K., Schwaag, S., Husstedt, I. W., \& Evers, S. (2003). Headache associated with sexual activity: Demography, clinical features, and comorbidity. Neurology, 61, 796-800.
K. S. Anand $(\bowtie) \cdot$ V. Dhikav

Department of Neurology, Postgraduate Institute of Medical Education and Research, Dr. Ram Manohar Lohia Hopsital, Guru Gobind Singh Indraprastha University, New Delhi 110001, India e-mail: kuljeet_anand@rediffmail.com 